\title{
Comunicação \\ Estimativa da produção de sementes de porta-enxertos cítricos por meio da massa de frutos
}

\author{
Moises Zucoloto ${ }^{1}$, Marcio Gama da Costa ${ }^{1}$, Lorena Moreira Carvalho ${ }^{2}$ \\ Dierlei dos Santos ${ }^{1}$, Dalmo Lopes de Siqueira ${ }^{3}$
}

\section{RESUMO}

A diversificação do uso de porta-enxertos é de suma importância, especialmente pelo fato de que a citricultura depara-se com um número crescente de doenças que afetam pomares enxertados. O objetivo foi determinar a quantidade de caixas de frutos necessária para a obtenção de uma massa determinada de sementes. Foram tomadas medidas de massa de fruto, número de frutos por caixa, número de sementes por fruto e número de sementes por caixa de nove porta-enxertos. O número máximo de caixas necessárias para obtenção de um quilo de sementes foi de 5,43 para o 'limão-cravo' e o número mínimo foi de 1,01, para o genótipo ‘Rangpur’ x ‘Swingle'.

Palavras-chave: Citrus, caixa e produção de mudas.

\section{ABSTRACT}

\section{Production estimation of citrus rootstock seeds using fruit weight}

Diversification of rootstocks is crucial, especially because the citrus industry is facing a growing number of diseases affecting orchards. The objective of this study was to determine the number of boxes of citrus needed to obtain a specific mass of seeds. Measurements of fruit weight, fruit number per box, number of seeds per fruit and seed number per box of nine rootstocks were recorded. The maximum number of boxes needed to obtain $1 \mathrm{~kg}$ of seeds was 5.43 for the Lemon 'Cravo' and the minimum was 1.01 for genotype Rangpur x Swingle.

Key words: Citrus, box, seedling production.

Recebido para publicação em março de 2010 e aprovado em janeiro de 2011.

${ }^{1}$ Engenheiros-Agrônomos, Mestres. Departamento de Fitotecnia, Universidade Federal de Viçosa, Av. PH Rolfs s/n, 36570 000, Viçosa, Minas Gerais, Brasil. moises.zucoloto@ufv.br, gamaesousa@gmail.com, dierlei.santos@ufv.br

Engenheira-Agrônoma. Departamento de Fitotecnia, Universidade Federal de Viçosa, Av. PH Rolfs s/n, 36570 000, Viçosa, Minas Gerais, Brasil. lorenamcarvalho@ yahoo.com.br Engenheiro-Agrônomo, Doutor. Departamento de Fitotecnia, Universidade Federal de Viçosa, Av. PH Rolfs s/n, 36570 000, Viçosa, Minas Gerais, Brasil. siqueira@ufv.br 


\section{INTRODUÇÃO}

A diversificação do uso de porta-enxertos é de suma importância, especialmente pelo fato de que a citricultura depara-se com um número crescente de doenças que afetam pomares enxertados, principalmente em limoeiro 'Cravo', o porta-enxerto mais utilizado no País (Bassanezi $e t$ al., 2003).

O Brasil é o maior produtor mundial de frutas cítricas, com 18,6 milhões de toneladas, além de ser o maior exportador mundial de suco de laranja concentrado, responsável por $81 \%$ do comércio mundial, com movimentação financeira de mais de US\$ 1 bilhão (Agrianual, 2008).

A utilização de mudas sadias e certificadas é medida de prevenção, indispensável para se evitar a ocorrência de doenças que vêm dizimando os pomares citrícolas brasileiros. No que se refere à produção de mudas cítricas, a utilização de porta-enxertos com reconhecida resistência a determinadas doenças constitui uma das etapas importantes na formação de pomares produtivos. Para sua produção, há necessidade de sementes de qualidade e em quantidades suficientes para atender à enorme demanda por mudas, sendo as sementes provenientes de plantas matrizes.

Existem vários estudos de frutos de porta-enxertos, objetivando melhor detalhamento, como o trabalho de Coelho et al. (2001) sobre tangerina, Passos et al. (2006) sobre laranja, Ramos et al. (2006) sobre limão, mas nenhum com o objetivo de determinar a quantidade necessária de massa de frutos de cada porta-enxerto para produção de certa quantidade de sementes.

Considerando esta necessidade, o presente trabalho teve como objetivo estimar o número de caixas que devem ser colhidas, de nove porta-enxertos cítricos tradicionais, para obtenção de sementes para facilitar a produção e beneficiar viveiristas, pesquisadores e produtores.

\section{MATERIAL E MÉTODOS}

O trabalho foi conduzido no município de Viçosa, Minas Gerais, localizado nas coordenadas geográficas $20^{\circ}$ $45^{\prime}$ de latitude sul e $42^{\circ} 51^{\prime}$ de longitude oeste, apresentando altitude média de $650 \mathrm{~m}$. O clima da região, segundo a classificação de Köppen, é do tipo Cwb, mesotérmico, com inverno seco e verão chuvoso. A temperatura média anual é de $19^{\circ} \mathrm{C}$, com a mínima em torno de $14^{\circ} \mathrm{C}$ e máxima de $26^{\circ} \mathrm{C}$

Frutos maduros de nove porta-enxertos foram colhidos, no mês de julho de 2009, em coleção experimental de porta-enxertos de citros, pertencente à UFV, sendo eles: limoeiro 'Cravo', citrandarim '1710', citrumeleiro 'Swingle', citrangeiro 'Carrizo', limoeiro 'Volkameriano', tangerineira 'Sunki', Citradia '1708', tangerineira 'Cleópatra' e 'Rangpur' x 'Swingle'. Os frutos colhidos de cada variedade foram acondicionados em caixas de $28 \mathrm{~L}$, com dimensões de $51 \times 31 \times 18 \mathrm{~cm}$, tomadas como referência.

Do total do número de frutos por caixa (NFC), selecionou-se amostra aleatória de 50 frutos, dos quais foram retiradas as sementes. Essas sementes foram lavadas em água corrente e submetidas à abrasão com cal hidratada, seguida de lavagem para retirada da mucilagem. Posteriormente, as sementes foram secas à sombra, durante 48 horas, à temperatura de $25^{\circ} \mathrm{C}$. Em seguida, foram contadas para determinação do número médio de sementes por fruto (NSF). A partir do NSF, estimou-se o número total de sementes por caixa (NSC). Com a massa das sementes extraídas dos 50 frutos (MS), obteve-se a massa de cada semente (MCS). A fim de se determinar o número necessário de caixas de frutos para se alcançar massa de $1 \mathrm{~kg}$ de sementes, multiplicou-se a massa de cada semente (MS) pelo número de sementes contidas em cada caixa. Diante da massa de sementes produzida por caixa, estimou-se quantas caixas seriam necessárias para produção de $1 \mathrm{~kg}$ de sementes.

Os dados foram submetidos à análise estatística descritiva, por meio do cálculo da média geral, e classificação das variedades que apresentavam valores acima e abaixo da média geral.

\section{RESULTADOS E DISCUSSÃO}

Levando-se em conta o número de sementes por fruto, um dos caracteres mais importantes na avaliação de um porta-enxerto, destacam-se os porta-enxertos 'Volkameriano', Citradia '1710' e 'Cleópatra', com 29,65, 21 e 16,8 sementes por frutos, respectivamente (Tabela 1).

O NSF, em estudo realizado por Passos et al. (2006), em Cruz das Almas, Bahia, apresentou valores próximos aos encontrados neste trabalho, demonstrando que as estimativas, aqui determinadas, podem ser utilizadas em outras regiões, facilitando a obtenção de sementes de acordo com a massa ou caixa de cada variedade. Entretanto, vale lembrar que, muitas vezes, por condições climáticas desfavoráveis, anos agrícolas diferentes, ou, até mesmo, diferentes plantas no mesmo pomar, podem apresentar número diferente de sementes por fruto.

O NFC para a maioria das espécies situou-se abaixo da média geral, por causa, principalmente, da tangerina 'Sunki', que elevou a média desta variável, por apresentar frutos de pequena dimensão. Em estudos realizados por Carvalho et al. (1997) com porta-enxerto 'Sunki', o NFC foi ligeiramente superior ao encontrado neste trabalho. Esta variedade apresentou o maior número de sementes por caixa e, por conseguinte, a menor massa individual de sementes, ao passo que a variedade 'Swingle' apresentou maior massa de sementes. 
Tabela 1. Características avaliadas dos nove porta-enxertos cítricos: NFC = número de frutos por caixa, NSF = número médio de sementes por fruto, NSC $=$ número de sementes por caixa, MS = Massa das sementes dos 50 frutos amostrados $(\mathrm{g})$, MCS = massa de cada semente $(\mathrm{g}), \mathrm{MSC}=$ massa média das sementes contidas na caixa $(\mathrm{g}), \mathrm{C}=$ número de caixas para produzir $1 \mathrm{~kg}$ sementes

\begin{tabular}{lccccccc}
\hline Variedades & NFC & NSF & NSC & MS & MCS & MSC & C \\
\hline Limão-cravo & $332 \mathrm{~b}$ & $14,06 \mathrm{~b}$ & $4664 \mathrm{~b}$ & $42 \mathrm{~b}$ & $0,0643 \mathrm{~b}$ & $299,89 \mathrm{a}$ & $5,34 \mathrm{a}$ \\
Citrandarim1710 & $452 \mathrm{~b}$ & $21,00 \mathrm{a}$ & $9491 \mathrm{~b}$ & $76 \mathrm{a}$ & $0,0760 \mathrm{~b}$ & $721,32 \mathrm{~b}$ & $2,33 \mathrm{~b}$ \\
Swingle & $199 \mathrm{~b}$ & $15,20 \mathrm{~b}$ & $3022 \mathrm{~b}$ & $88 \mathrm{a}$ & $0,1239 \mathrm{a}$ & $374,43 \mathrm{a}$ & $4,25 \mathrm{a}$ \\
Carrizo & $415 \mathrm{~b}$ & $13,46 \mathrm{~b}$ & $5583 \mathrm{~b}$ & $70 \mathrm{a}$ & $0,1124 \mathrm{a}$ & $627,53 \mathrm{~b}$ & $2,84 \mathrm{~b}$ \\
Volkameriano & $149 \mathrm{~b}$ & $29,56 \mathrm{a}$ & $4392 \mathrm{~b}$ & $122 \mathrm{a}$ & $0,0854 \mathrm{~b}$ & $375,08 \mathrm{a}$ & $4,08 \mathrm{a}$ \\
Sunki & $2909 \mathrm{a}$ & $9,36 \mathrm{~b}$ & $27228 \mathrm{a}$ & $20 \mathrm{~b}$ & $0,0478 \mathrm{~b}$ & $1301,50 \mathrm{~b}$ & $1,18 \mathrm{~b}$ \\
Citradia 1708 & $421 \mathrm{~b}$ & $12,42 \mathrm{~b}$ & $5226 \mathrm{~b}$ & $60 \mathrm{~b}$ & $0,1051 \mathrm{a}$ & $549,25 \mathrm{a}$ & $3,26 \mathrm{a}$ \\
Cleópatra & $772 \mathrm{a}$ & $16,80 \mathrm{a}$ & $12972 \mathrm{a}$ & $70 \mathrm{a}$ & $0,0886 \mathrm{a}$ & $1149,32 \mathrm{~b}$ & $1,58 \mathrm{~b}$ \\
Rangpur x Swingle & $1213 \mathrm{a}$ & $13,34 \mathrm{~b}$ & $16187 \mathrm{a}$ & $58 \mathrm{~b}$ & $0,0940 \mathrm{a}$ & $1521,56 \mathrm{~b}$ & $1,01 \mathrm{~b}$ \\
Média geral & 762 & 16,13 & 9863 & 67 & 0,0886 & 873,86 & 2,88 \\
\hline
\end{tabular}

$\mathrm{a}=$ valor acima da média geral, $\mathrm{b}=$ valor abaixo da média geral.

Dentre os porta-enxertos estudados, o limão- 'cravo' foi o que apresentou a menor massa de sementes por caixa, sendo necessárias 5,34 caixas de frutos para produção de $1 \mathrm{~kg}$ de sementes, ao passo que o genótipo 'Rangpur' $\mathrm{x}$ 'Swingle' foi o que demonstrou a maior massa de sementes por caixa, requerendo-se apenas 1,01 caixa para se obter $1 \mathrm{~kg}$ de sementes.

\section{CONCLUSÕES}

O número máximo necessário de caixas para obtenção de um quilo de sementes foi de 5,43 para o limão- 'cravo' e o mínimo foi de 1,01 para o genótipo 'Rangpur' x "Swingle".

\section{AGRADECIMENTOS}

Ao CNPq pelo apoio financeiro.

\section{REFERÊNCIAS}

Agrianual (2008) Anuário da agricultura brasileira. São Paulo, Instituto FNP. 552p.

Bassanezi RB, Fernandes NG \& Yamamoto PT (2003) Morte súbita dos citros. Araraquara, Fundecitrus. 54p.

Carvalho MRT, Bordignon R, Ballve RML, Pinto-Maglio CAF \& Medina Filho HP (1997) Aspectos biológicos do reduzido número de sementes da tangerina 'Sunki'. Bragantia, 56:60

Coelho RI, Lopes JC, Groth D \& Souza NA (2001) Caracterização morfológica da planta, frutos, sementes e plântulas de tangerina (Citrus reticulata) de ocorrência natural no sul do estado do Espírito Santo. Revista Brasileira de Sementes, 23:294-301.

Passos OS, Peixouto LS, Santos LC, Caldas RC \& Soares Filho WS (2006) Caracterização de híbridos de Poncirus trifoliata e de outros porta-enxertos de citros no estado da Bahia. Revista Brasileira de Fruticultura, 28:410-413.

Ramos JD, Araújo Neto SE, Castro NEA, Martins PCC \& Correia MG (2006) Poliembrionia e caracterização de frutos de Citrumelo 'Swingle' e de Poncirus trifoliata. Ciência e Agrotecnologia, 30:88-91. 